\title{
An Analysis between Traditional and Motion Detection Game - using ICT Techniques
}

\author{
M. Kannan ${ }^{1 *}$, M. Geetha ${ }^{1}$ and J. Sujatha ${ }^{2}$ \\ 'Department of CSA, SCSVMV University, Kanchipuram, India; \\ saikannan1999@rediffmail.com \\ ${ }^{2}$ MCA Department, Arulmigu Meenakshi Amman College of Engineering, \\ Vadamavandal, India
}

\begin{abstract}
Human relaxation and stress management always need different forms of entertainment. Soft games generate concentration and focus on objects. The modern games with latest ICT tools are preferred by youngster, especially college students. By keeping this background as the base for the study, the present study chose the students who had the experience of playing games through traditional and modern sources as sampling unit and required data were collected through systematic opinnaire. The collected output were analysed for the comparison of play consistency in both traditional and modern sources. It concludes for the effectiveness of play consistency in modern games.
\end{abstract}

Keywords: Games, ICT, Motion Detection, Traditional

\section{Introduction}

Play is the part of human life since from the day of childhood to adolescent and even may be extended to next stages. But the form of play comprises the methods of physical, mental, psychological or the combination of all above said. The type of game or play chosen by individuals depends upon their generation and availability. In this aspect, among the present day generation, comparing to outdoor games, indoor games occupy major space. In addition to that among the indoor games, mental and mind enrichment games with the help of electronic media, especially with the support ICT tools occupy major contribution and revelation ${ }^{1}$. It is observed that, the computer games preferred by present day youngsters ${ }^{2}$ belong to both traditional and modern categories. But both traditional and modern categories involve the application of ICT tools. But the inclusion of ICT elements through the mode of interactive element and space differ both in traditional and modern games.
The traditional games comprise the play space with the less interactive process and physical oriented ICT tools, where in which modern game space comprise the advanced ICT interactive elements like motion cameras ${ }^{3,4}$, interactive graphical user interface, reversion process and so on. In addition to that, both traditional and modern games try to give attention ${ }^{5}$, relaxation, mind exercises ${ }^{6}$, psychological boost up, enhance motivation ${ }^{7}$, focus elevation and stress management. But the play consistency in terms of usage volume, usage space, user retention, preference of replay needed to be verified in terms of traditional and modern games.

By keeping this view in mind, the present study has been narrated as the comparative study for verifying the play consistency experienced by the players both in traditional and modern games with special reference to Mario game. The selected test group for the study tested for their experience of playing both traditional and modern forms of games. The study focused on testing Mario games, since it is the game which is played for years together

*Author for correspondence 
among the youngster community both in traditional and modern forms.

In addition to that, it is the game in which the technology upgrading through the special application of ICT tools are done on consistent basis. It is the game where the interest shown by players belongs to strong heterogeneous background. These aspects invoked the reason for undertaking this study with the focus of comparing play consistency experienced by players both in traditional and modern games with elevated application of ICT tools. The play consistency comprises the aspects of duration of play, space for play, retention viability of the game both in traditional and modern sources, preference of testing at different modes or levels by users.

\section{Literature Review}

Alastair H. Cummings ${ }^{8}$ studied the evolution of game controller and control schemes, also examined the effect of the design of controller on games and vice-versa. Thomas B. Moeslund and Erik Granum ${ }^{9}$ discussed about the various work related to computer vision based motion capture from 155 published papers. John J. Magee et al. ${ }^{10}$ developed BlockEscape game using face tracker and eye analysis system. It will run on any computer without need for any expensive equipment. The experiment result is tested with four users and the result is compared with camera mouse. The developed games produce good results.

Ru-Chu Shih et al. ${ }^{11}$ conducted a study to determine the effectiveness of webcam motion sensor game for 3 autistic students. The result reveals that it enhances positive attitude, enhance enthusiastic and improves in heartbeat, blood pressure, body temperature, muscle and cardiovascular function. Kristian Kiili et al. ${ }^{12}$ examined mobile multiplayer exertion game. Tuck of War, Diamond Hunter and heart rate are the games taken for the study and tested with school students $(n=105)$. The result reveals that motion detection game plays a vital role in education and it fight against obesity problem.

Ameerani Jarbandhan ${ }^{3}$, discussed about three major areas such as body structure analysis, tracking of human motion using camera's and recognizing human activities, application for sport and current possibilities in human motion analysis. Santiago Hors Fraile et al. ${ }^{13}$ discussed about the various exercise games available for elderly persons. They developed demo software called SANDRA to handle user's movement. Ulf Hagen ${ }^{14}$ discussed about origin of game concept and described different domains that game design ideas were drawn. It also discussed about game design ideas such as recycled part and inventive part.

Stephan A. Drab ${ }^{15}$, discussed about common interaction techniques, concept, common tracking algorithms, motion detection algorithms and demonstrators for motion detection as interaction technique on mobile devices. Michael Soppitt and Graham McAllister ${ }^{16}$ had taken three games such as Cops and Robbers, iDroids Mania and Inspector Gadget to determine behavioural difference between games of both high and poor quality. 10 participants are taken for the study. The result reveals that engagement is the significant factor for good games that keeps them to stay for longer duration.

Sagar N. Purkayastha et al. ${ }^{17}$ analyzed and compared the low cost gaming devices, the Nintendo Wiimote and the Sony Playstation 3 (Sixaxis), in terms of their accuracy and resolution. Isabela Granic et al. ${ }^{5}$ discussed about benefits of playing video games over four domains such as cognitive, motivational, emotional, and social.

Thus various studies have been made in analyzing the origin of games, its development and in creating new games. This study is unique for its particular case based approach. In this work, a game Mario is taken for the study and a cross comparison is made among the users with opinion prevailing in them, by applying the game with traditional and motion based approach. Here, the sample size is much more when compared to the previous studies and thus can provide better authentication for the results.

\section{Objectives of the Study}

- To understand the demographic profile of the respondents.

- To determine the reasons for playing video games.

- To outline the reasons for playing traditional games and motion detection games in Mario.

- To compare the opinion about traditional games and motion detection games in Mario.

\section{Methodology}

In this work, Mario game is taken as a case study and uses the survey technique for collecting data to meet out the objectives. A pilot study was conducted to ensure the feasibility of the questionnaire and obtained value 
of Cronbach coefficient is above 0.83 , it indicates that questionnaire is suitable for further analysis. Data was collected from a private engineering college located in Kanchipuram town, the students are the respondents for the study and obtained sample size for the study is 500 . Simple random technique was adopted and SPSS 20 tool is used to analyze the results.

\section{Results and Discussion}

\subsection{Demographic Profile of the Respondents}

Among 500 respondents, 59\% of respondents were male and $41 \%$ of respondents were female, $36.8 \%$ and $63.2 \%$ of respondents were below 20 and above 20 age category. According to education qualification, $24 \%, 12.2 \%, 12.2 \%$, $39.6 \%$ and $12 \%$ of respondents belong to $\mathrm{BE}$ (EEE), $\mathrm{BE}(\mathrm{ECE}), \mathrm{BE}(\mathrm{Mech}), \mathrm{BE}(\mathrm{CSE})$ and ME. As for as year of study, $30 \%, 42 \%, 14 \%$ and $14 \%$ of respondents belong to I year, II year, III year and IV year category.

\subsection{Opinion about Playing Video Games}

The result indicates that $100 \%$ of respondents had play video games. $86.4 \%$ and $13.6 \%$ of respondents belong to active video player and non-active video player. $61 \%$, $26.2 \%$ and $12.8 \%$ of respondents agreed that they are playing video games, less than 3 years, 4 to 6 hours and above 6 hours per week category. 22\% of respondents agreed, playing video games gives enthusiastic, $68 \%$ of respondents agreed that it gives happy and 10\% of respondents agreed that it does not give happy. $79.4 \%$ of respondents said that there are no difficulties when playing video games and $20.6 \%$ of respondents said that they have experienced difficulties when playing video games.

\subsection{Hypotheses}

Ho: There is no significant difference between gender and playing video games at 5 percent level of significance.

Ha: There is significant difference between gender and playing video games at 5 percent level of significance.

\section{Inference}

From the Table 1, it is clear that significant value is less than 0.05 , hence Ho is rejected and concluded that there is significant difference between gender and playing video games.

\section{Hypotheses 2}

Ho: There is no significant difference between educational qualification and playing video games at 5 percent level of significance.

Ha: There is significant difference between educational qualification and playing video games at 5 percent level of significance.

\section{Inference}

From the Table 2, it is clear that significant value is less than 0.05 , hence Ho is rejected and concluded that there is significant difference between education qualification and playing video games.

\section{Hypotheses 3}

Ho: There is no significant difference between year of study and playing video games at 5 percent level of significance.

Table 1. Gender Vs Playing Video Games

\begin{tabular}{lccccc}
\hline & Sum of Squares & Df & Mean Square & F & Sig. \\
\hline Between Groups & 1.271 & 1 & 1.271 & 4.178 & .041 \\
Within Groups & 151.529 & 498 & .304 & & \\
Total & 152.800 & 499 & & & \\
\hline
\end{tabular}

Source: Primary data

Table 2. Education Qualification Vs Playing Video Games

\begin{tabular}{lccccc}
\hline & Sum of Squares & Df & Mean Square & F & Sig. \\
\hline Between Groups & 76.079 & 4 & 19.020 & 9.215 & .001 \\
Within Groups & 1021.703 & 495 & 2.064 & & \\
Total & 1097.782 & 499 & & & \\
\hline
\end{tabular}

Source: Primary data 
Ha: There is significant difference between year of study and playing video games at 5 percent level of significance.

\section{Inference}

From the Table 3, it is clear that significant value is less than 0.05 , hence Ho is rejected and concluded that there is significant difference between year of study and playing video games.

\subsection{Opinion about Traditional Games}

The Table 4 shows the opinion about playing Mario game in Traditional system like satisfaction, frustration, welcoming, good exercise, pleasure, disappointment, energetic and referring factors.

\subsection{Inference}

From the Table 4 and Figure 1 it is seen that opinion about playing Mario in traditional games. Based upon highest mean, it is identified as the respondents felt more energetic when playing Mario in traditional games [Mean value = 2.24], the next factor seems to be the respondents felt disappointed because playing Mario in traditional games is nowadays slowly disappearing [Mean value $=2.19$ ] . The last factors seems to be respondents opinion about satisfied with the controls of Mario game in traditional games $[$ Mean value $=2.02]$.

\subsection{Opinion about Motion Detection Game}

The Table 5 shows the opinion about playing Mario game in Motion detection system like satisfaction, frustration, welcoming, good exercise, pleasure, disappointment, bored, energetic and referring factors.

\subsection{Inference}

From the Table 5 and Figure 2 it is seen that opinion about playing motion detection games. Based upon highest mean, the respondents felt more energetic when

Table 3. Year of Study Vs Playing Video Games

\begin{tabular}{lccccc}
\hline & Sum of Squares & Df & Mean Square & F & Sig. \\
\hline Between Groups & 33.728 & 3 & 11.243 & 5.241 & .001 \\
Within Groups & 1064.054 & 496 & 2.145 & & \\
Total & 1097.782 & 499 & & & \\
\hline
\end{tabular}

Source: Primary data Inference

Table 4. Playing Mario in Traditional System

\begin{tabular}{lc}
\hline Factors & Mean \\
\hline I am satisfied with the controls of Mario game in Traditional Games & 2.02 \\
I am frustrated when I could not able to use controls of Mario in Traditional & 2.1 \\
Games & \\
I am welcoming this kind of innovative and technological Mario game in & 2.05 \\
Traditional Games & 2.17 \\
Traditional Games is good exercise for mind and body when playing in & \\
Mario Games & 2.06 \\
I never experienced in my life this kind of pleasure before playing Mario in \\
Traditional Games \\
$\begin{array}{l}\text { I am disappointed because traditional game in Mario nowadays slowly } \\
\text { disappearing }\end{array}$ \\
$\begin{array}{l}\text { I am bored when playing Mario in Traditional Games } \\
\text { I am feeling energetic or great after playing Mario in Traditional Games }\end{array}$ \\
$\begin{array}{l}\text { I will suggest my friends, relatives and others to play Mario in Traditional } \\
\text { Games }\end{array}$ \\
\hline Source: Primary data & 2.18 \\
\hline
\end{tabular}




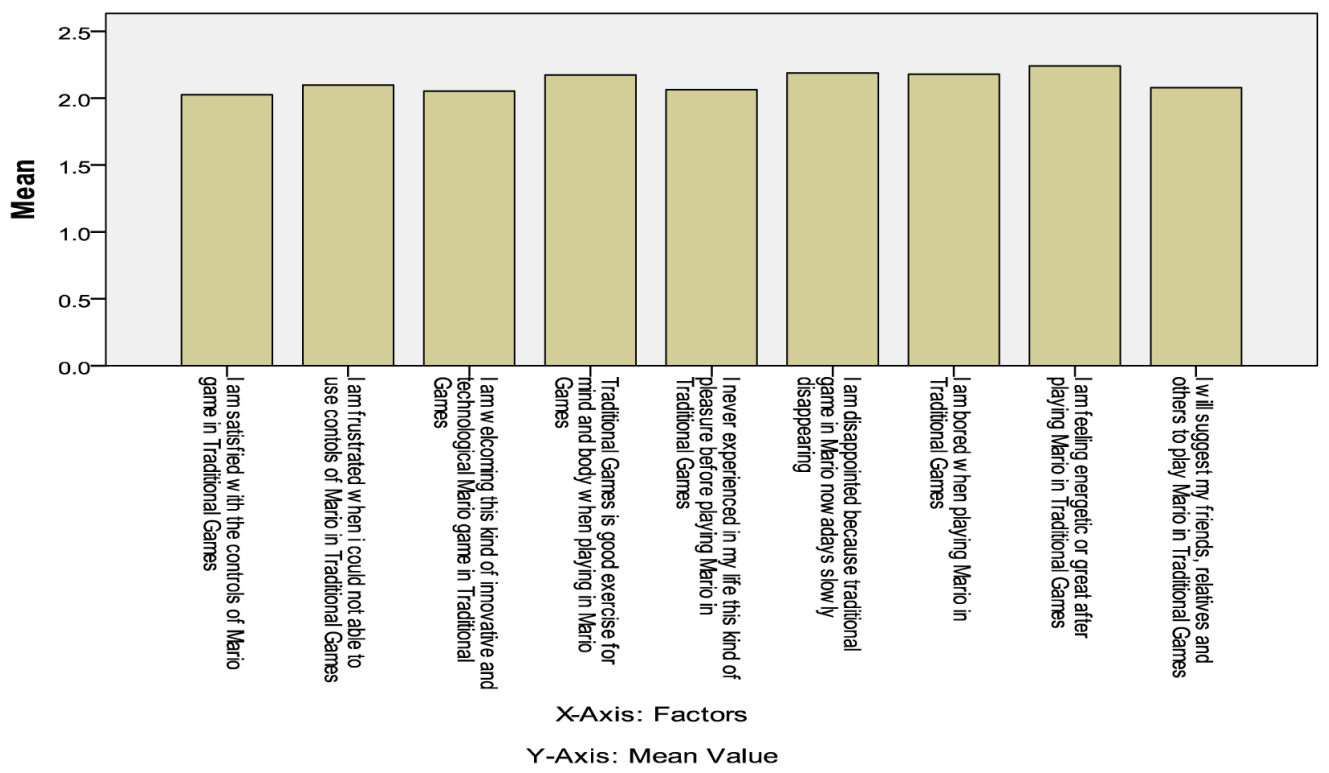

Figure 1. Traditional game.

Table 5. Playing Mario in Motion Detection System

\begin{tabular}{lc}
\hline Factors & Mean \\
\hline I am satisfied with the controls of Mario game in Motion Detection Games & 2.17 \\
I am frustrated when I could not able to do eye and body coordination in Motion Detection Games & 2.32 \\
I am welcoming this kind of innovative and technological Mario game in Motion Detection Games & 2.41 \\
When playing Mario games in Motion Detection is good exercise for mind and body happily & 2.57 \\
I never experienced in my life this kind of pleasure before playing Mario in Motion Detection Games & 2.33 \\
I am disappointed because there are only a few games to play in Motion Detection games & 2.34 \\
I am bored when playing Mario games in Motion Detection Games & 2.28 \\
I am feeling energetic or great after playing Mario in Motion Detection Games & 3.05 \\
I will suggest my friends, relatives and others to play Mario in Motion Detection Games & 2.39 \\
\hline
\end{tabular}

Source: Primary data

playing Mario in Motion detection games [Mean value = 3.05], the next factors indicates that the respondents felt happily for mind and body when playing Motion Detection games [Mean value $=2.57$ ]. The last factor indicates that respondents are satisfied with controls to playing Mario in motion detection games [Mean value $=2.17$.

\subsection{Comparative Study of Traditional and Motion Detection Game}

The comparative study is conducted to review the opinion about playing Mario game in traditional and motion detection system is as shown in table 6 and figure 3.
Table 6. Comparison between Traditional and Motion Detection Game

\begin{tabular}{lc}
\hline System & Mean \\
\hline Traditional Game & 2.12 \\
Motion Detection Game & 2.43 \\
\hline Source: Primary data &
\end{tabular}

\subsection{Inference}

From the Table 6 and Figure 3, it is understood that the overall obtained mean value for traditional games is 2.12 and motion detection game is 2.43. The results were clearly indicated that higher number of students respondents showing interest towards motion detection games rather than traditional games. 


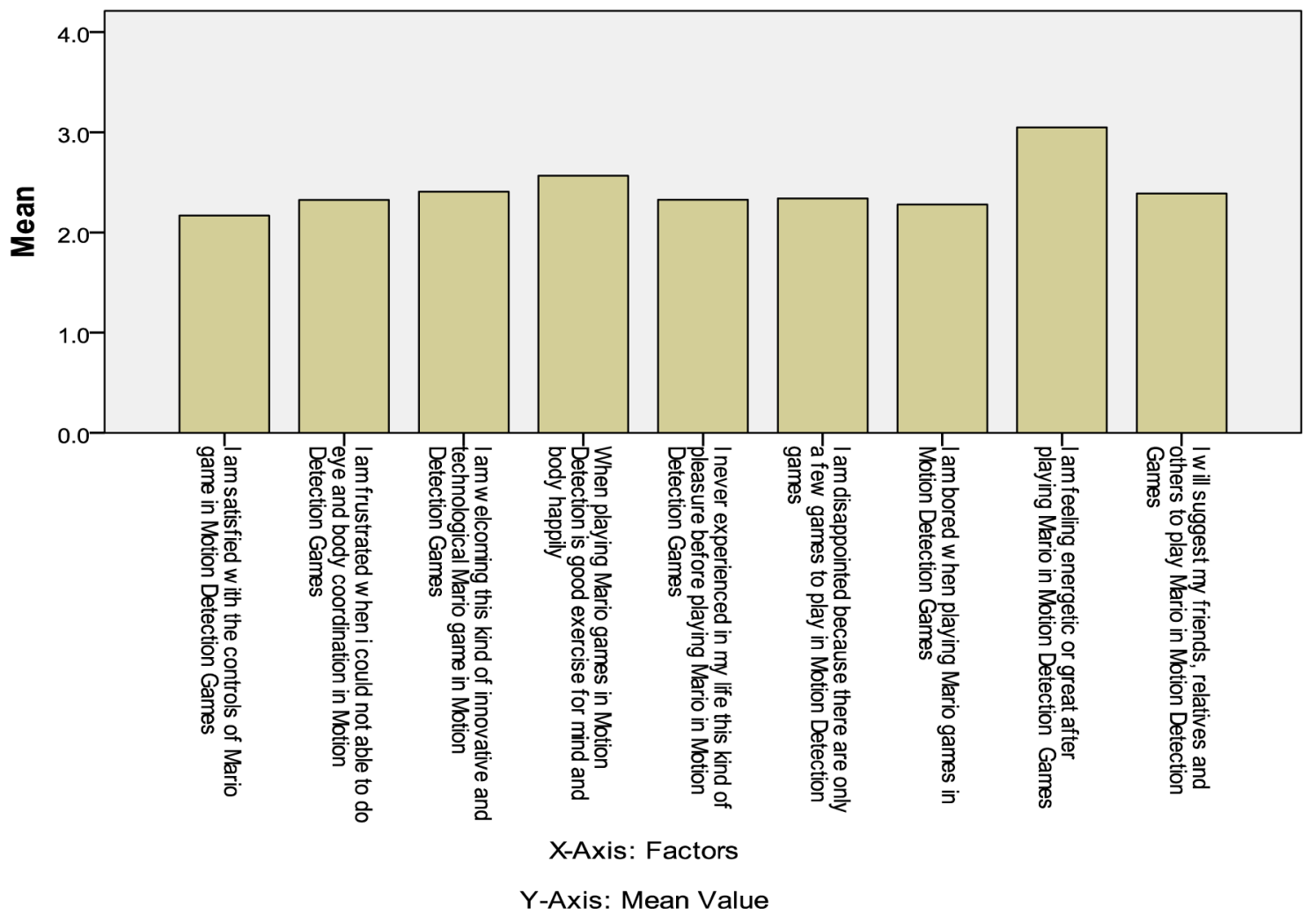

Figure 2. Motion Detection Game.

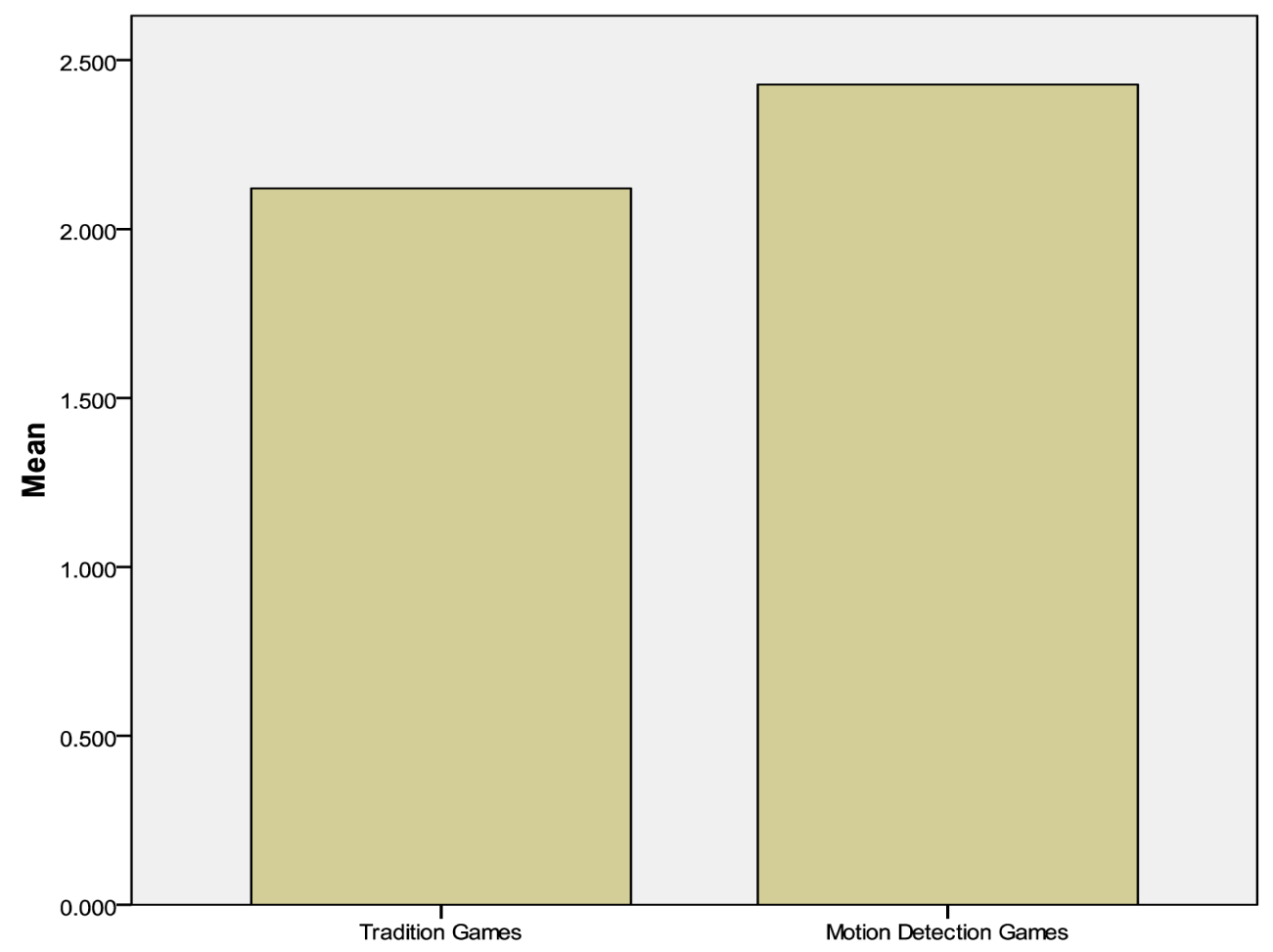

Figure 3. Comparision between Traditional game and Motion Detection Game. 


\section{Conclusion}

The original problem statement was to evaluate the analysis between traditional games and motion detection games from the respondent's perspective. The basic criteria were to evaluate the respondent's interest on computer games, particular Mario game. The point of interest was therefore not only satisfaction/fulfillment but also whether respondents can really use them efficiently. The analysis about playing Mario game in traditional system and motion detection system were done using SPSS 20 among the engineering college students. The respondents from engineering college students were participated with full involvement and polled their opinion. The analysis results were clearly indicated that the higher number of respondents shown their interest towards playing Mario in motion detection game rather than traditional game.

The study has certain limitations as Mario game is alone taken as a case study, opinions are obtained from a private engineering college and limited factors are taken for the study. For further research, satisfaction and dissatisfaction factors may be identified, playing games can have an impact on education may be studied and more number of case studies may be considered.

\section{References}

1. Alsuraihi MD. Information and Communication Technologies 'ICTS' in the Saudi Household. Journal of Asian Scientific Research. 2013; 3(3):286-307.

2. Muros B, Aragón Y, Madrid AB. Youth's Usage of Leisure Time with

3. Video Games and Social Networks. Scientific Journal of Media Education. 2013; 20(40): 31-9. ISSN:1134-3478

4. Jarbandhan A. Recent Developments in Human Motion Analysis. Regional Sport Conference; 2013; Suriname. P. $1-39$.

5. Kondori FA. Human Motion Analysis for Creating Immersive Experience. 2012. p. 1-85.
6. Granic I, Lobel A, Engels RCME. The Benefits of Playing Video Games. American Psychological Association. 2013; 69(1):66-78.

7. Scott Steinberg. Why Video Games are Good for You. p. $1-8$.

8. Grimley M, Green R, Nilsen T, Thompson D. Comparing computer game and traditional lecture using experience ratings from high and low achieving students. Australasian Journal of Educational Technology. 2012; 28(4):619-38.

9. Cummings AH. The Evolution of Game Controllers and Control Schemes and their Effect on their games. p.1-8.

10. Moeslund TB, Granum E. A Survey of Computer VisionBased Human Motion Capture. Computer Vision and Image Understanding. 2011; 81:231-68.

11. Magee JJ, Scott MR, Waber BN, Betke M. EyeKeys: A Realtime Vision Interface Based on Gaze Detection from a Low-grade Video Camera. IEEE. 2004; 1-8.

12. Ru-Chu S, Kun-Hsien L, Shi-Jer L, Huei-Yin T. The Effects of Applying Game-Based Learning to Webcam Motion Sensor Games for Autistic Students' Sensory Integration Training. The Turkish Online Journal of Educational Technology. 2012 Oct; 11(4):451-9.

13. Kiili K, Perttula A, Tuomi P. Development of Multiplayer Exertion Games For Physical Education. IADIS International Journal on WWW/Internet. 8(1):52-69

14. Fraile SH, Browne J, Brox E, Evertsen G. Suitability analysis of commercial open-source driven motion sensor devices applied to exergames for the elderly. p. 1-4.

15. Hagen U. Where Do Game Design Ideas Come From? Invention and Recycling in Games Developed in Sweden. Proceedings of DiGRA. 2009; 1-11.

16. Stephan A. Drab Motion Detection as Interaction Technique for Games \& Applications on Mobile Devices. p. 1-33.

17. Soppitt M, McAllister G. Understanding Player Experience Using Sequential Analysis. Proceedings of DiGRA Conference; 2011; p. 1-19.

18. Purkayastha SN, Eckenstein N, Byrne MD, O’Malley MK. Analysis and Comparison of Low Cost Gaming Controllers for Motion Analysis. IEEE/ASME International Conference on Advanced Intelligent Mechatronics Montréal; 2010 Jul 6-9; Canada. P. 353-60. 